\section{Ulimital gDepartment.}

CONTRIBUTIONS FROM THE OR'THOPEIOIC DEPAR'TMEN'T OF 'THE CARNEY HOSPI'TAL.

\section{OSTEOSARCOMA OF TIIE ELBOW.}

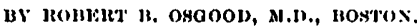

The patient was a pale, slender woman, 29 year's old; married at twenty and the mother of six children. The family history and the past history were negative. She eame to the OutPatient Departnent on Sept. 21, 1900, because of pain and swelling over the outer side of her right elbow. 'This liad heen of one year's dura-

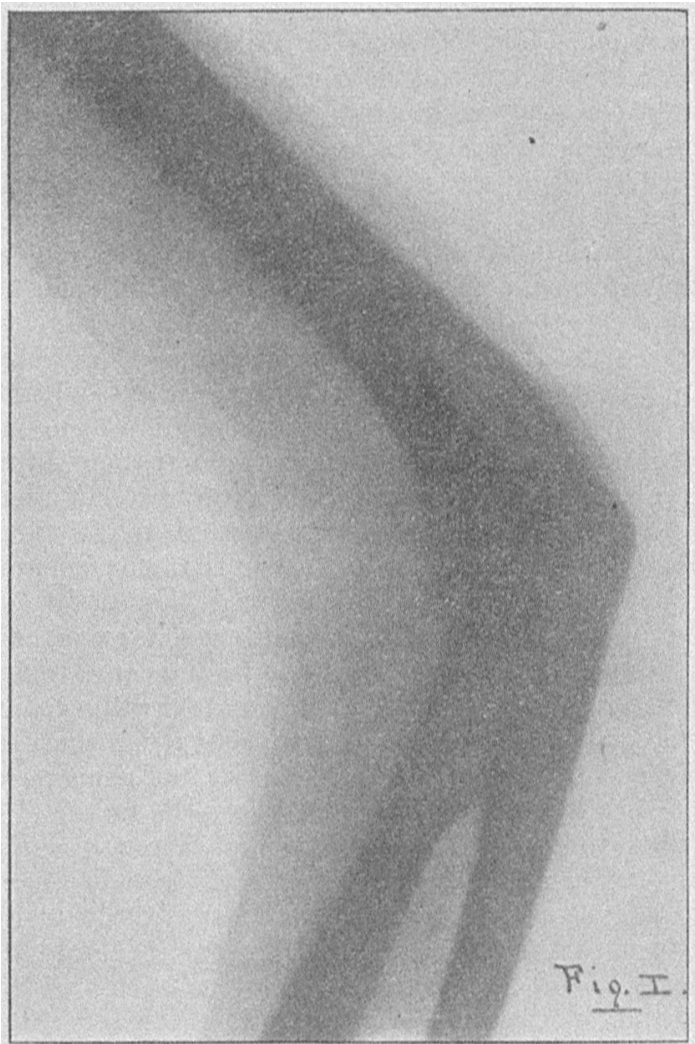

tion, and the condition had varied in severity. There had been periods when there was superficial inflammation, the swelling greater and the pain worse. 'The only constint symptom had been a certain limitation of motion. No other joints had at any time been involved. There was no definite listory of injury.

The examination showed an ellow slightly swollen over the outer condyle lut without acute inflammation. Flexion was possible to a little beyond a right angle, and extension to within $45^{\circ}$ of straight. Rotation was limited. The axillary glands were slightly enlarged. No positive diagnosis was made. A rheumatoid condition with the atrophic changes taking place was considered, as were also a tubercular lesion and an osteo- myelitis. The only sign suggesting malignancy was the slight enlargement of the axillary glands.

An $x$-ray to further establish the diagnosis, was taken and is shown in Fig. I. 'The negative was a surprise, and showed a definite lone lesion; evidently there was a myelitis of some sort, with either a bone cyst or aluscess cavity communicating with the joint.

The patient could enter only on a free bed. The hospital was full, and there being no acute symptoms, slie was placed on the waiting list of applicants. 'The diagnosis of a low grade osteomyelitis with suppuration was suggested; immobilization applied and tonic treatment advised. When the chance for entrance came, either the notification was never sent, or the patient failed

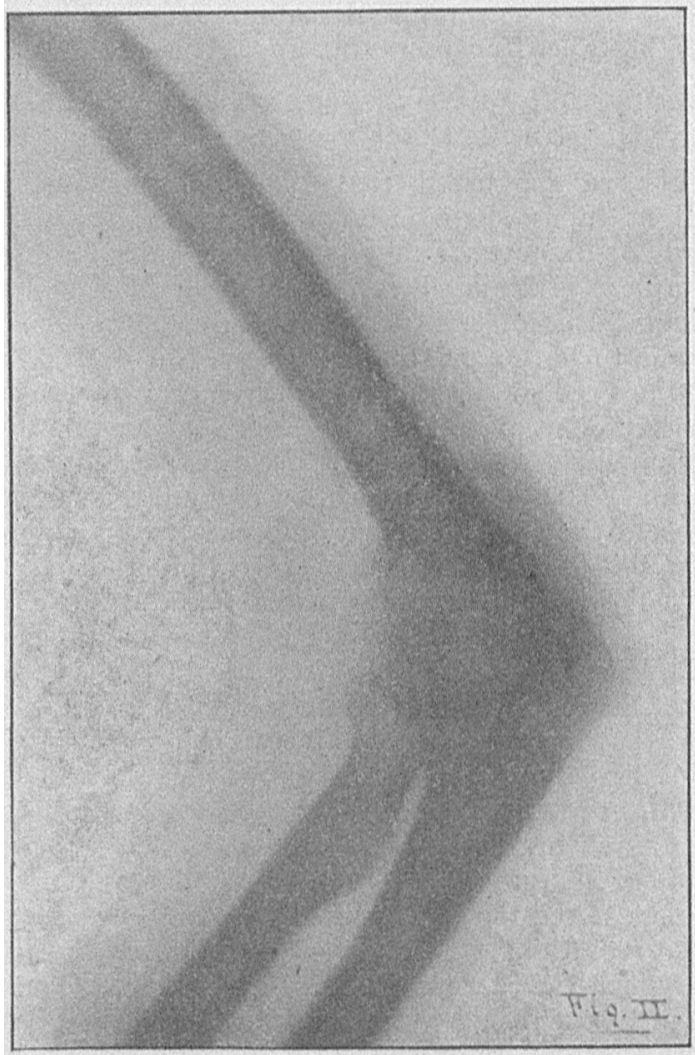

to respond, for nothing was heard from her until slie appeared at the Ont-l'atient on March 8, 1901, six months after she had first been seen. The mobility was practically the same as at the first examination. There was no swelling or tenderness, and pain only on extremes of motion. A bony spur could be felt about a half an incli above the external condyle. The patient reported simply for observation, and her only discomfort was in using the right arm for feeding herself and dressing her hair.

The case becomes somewhat humiliating at this point, for a greater experience in interpretation of $x$-ray plates might have suggested the correct final diagnosis. The skiagraph (Fig. II) now taken showed what was thought to be a partial 
healing of the old cavity, but enough attention was not paid to a raritication of the bone structure in the condyles. She was advised to report at short intervals, but the next note of her appearance is on May 27, 1901, eight months after the first examination, two months after the last note and $x$-ray. She reported because of pain and swelling over the inner condyle. The ellow had continued to cause her slight inconvenience, until one day she had wrenched her arm in hanging out clothes, and the acute symptoms had followed almost immediately upon the trauma. The motion of the elbow was much less free than at any previous observation; there was more swelling and the skin had a somewhat angry look. The process still seemed wholly local. An $x$-ray at

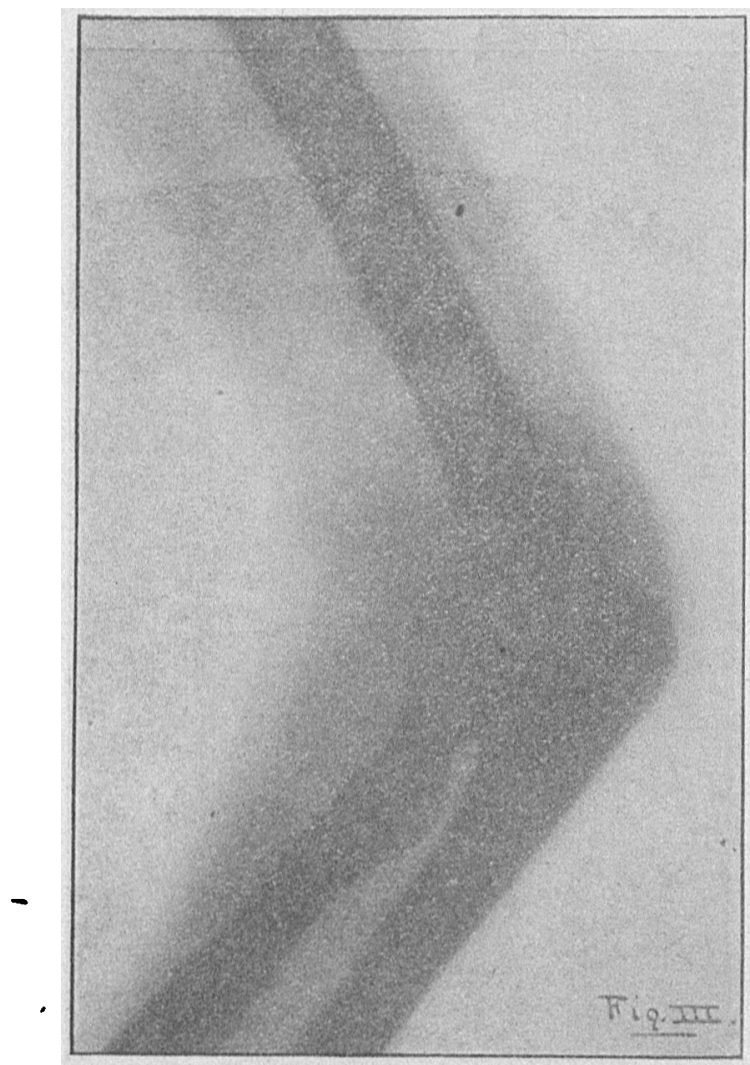

this time (Fig. III) was at once suggestive of the real condition. There had been a spontaneous fracture above the condyles and the more general involvement of the bone by the process was evident.

In the hospital an exploratory incesion by J)r. Goldthwait revealed a highly vascular neoplastic growth. The report of the microscopical examination of the tissue by Dr. Pratt of the Pathological Department of the Harvard Medical School is subjoined.

Gross examination.-T' 'wo small pieces of soft, grayish, homogeneous, translucent tissue, each aloout $4 \mathrm{~mm}$. in dianeter.

Micioscopic examination. - The tissue consists of closely packed cells, with round and oval vesicular neuclei; the cell outlines are not distinct. 'There is but little intercellular substance. Numerous thin-walled blood vessels pass among the tumor cells. Mitotic figures are common, hence the tumor is growing with considerable rapidity.

Dingnosis.-Round-celled sarcoma.

The patient was transferred to the Surgical Service, and by the courtesy of Dr. W. A. Pease I am enabled to report the short subsequent history.

The arm was amputated at the point of election on June 25, 1901. 'The patient insisted upon having the arm interred in the family lot, and examination of the gross specimen was permitted only so far as to show the marked bony involvement which the $x$-ray indicated. The patient was discharged relieved on July 7, after an un. cventful convalescence with a firmly healed first intention stump. I have seen the patient on Jan. 23, 1902. She is in excellent health; no axillary glands or other signs of recurrence could be discovered. 'The scar is soft and withont nodules. She is caring for six children, and about to be confined with a seventh.

'The case has seemed to me worth reporting for three reasons: (1) Because it teaches the necessity of more careful and experienced interpretation of $x$-ray negatives, and their great value when so interpreted; (2) because the history and subjective symptoms are not those we usually associate with a neoplasm as malignant and rapidly growing as the pathological examination revealed this to be; $(3)$ because in the light of recent experiments it scems possible that the application of the $x$-ray, while perbaps not materially retarding the growth, exercised an analgesic effect, and may have been partially responsible for the few symptoms. Thus, without accurate interpretation and good technique, this method of examination and valuable therapeutic measure may actually olsscure the diagnosis.

\section{AN UNUSUAL FAMIIY HISTORY OF TU- BERCULOSIS.}

BY A. H. WILLAMS, M.D., HostroN.

How $A$ lid $C$. and Frances $C$, ages respectively 23 and 21 , a brother and sister, are both suffering with tubercular bone disease. Howard has a lesion of the knee, two and one-half years in duration, which has been doing well since excision, eighteen months ago. He injured his knee in boybood. Frances had tuberculosis of the hip joint, following a fall firom a carriage when she was three years old. This lesion seems to be quiescent, but she developed an acute tuberculosis of the shoulder three montlis ago, and has had it excised. Her shoulder has lieen lame from an injury for many years.

'Their mother, Mrs. C., nearly died twenty years ago from pulmonary tuberculosis, but recovered and now seems well. Her family history is of some interest. Her mother was one of three sis- 